\title{
BMJ Open Evaluation of the initial implementation of a nationwide diabetic retinopathy screening programme in primary care: a multimethod study
}

\author{
Vincent Khou (D) , ${ }^{1,2}$ Muhammad Azaan Khan, ${ }^{3}$ Ivy Wei Jiang, ${ }^{3}$ Paula Katalinic, ${ }^{1,2}$ \\ Ashish Agar, ${ }^{1,3,4}$ Barbara Zangerl ${ }^{2,5}$
}

To cite: Khou V, Khan MA, Jiang IW, et al. Evaluation of the initial implementation of a nationwide diabetic retinopathy screening programme in primary care: a multimethod study. BMJ Open 2021;11:e044805. doi:10.1136/ bmjopen-2020-044805

- Prepublication history and additional supplemental material for this paper are available online. To view these files, please visit the journal online. (http://dx.doi.org/10.1136/ bmjopen-2020-044805).

Received 23 October 2020 Accepted 29 July 2021

Check for updates

(C) Author(s) (or their employer(s)) 2021. Re-use permitted under CC BY-NC. No commercial re-use. See rights and permissions. Published by BMJ.

${ }^{1}$ Centre for Eye Health, Sydney, New South Wales, Australia ${ }^{2}$ School of Optometry and Vision Science, Faculty of Medicine and Health, University of New South Wales, Sydney, New South Wales, Australia

${ }^{3}$ Faculty of Medicine and Health, University of New South Wales, Sydney, New South Wales, Australia

${ }^{4}$ Department of Ophthalmology, Prince of Wales Hospital, Sydney, New South Wales, Australia

${ }^{5}$ Coronary Care Unit, Royal Prince Alfred Hospital, Sydney, New South Wales, Australia

Correspondence to

Dr Barbara Zangerl;

zangerlb@gmail.com

\section{ABSTRACT}

Objectives The Australian Government funded a nationwide diabetic retinopathy screening programme to improve visual outcomes for people with diabetes. This study examined the benefits and barriers of the programme, image interpretation pathways and assessed the characteristics of people who had their fundus photos graded by a telereading service which was available as a part of the programme.

Design Multimethod: survey and retrospective review of referral forms.

Setting Twenty-two primary healthcare facilities from urban, regional, rural and remote areas of Australia, and one telereading service operated by a referral-only eye clinic in metropolitan Sydney, Australia.

Participants Twenty-seven primary healthcare workers out of 110 contacted completed a survey, and 145 patient referrals were reviewed.

Results Manifest qualitative content analysis showed that primary healthcare workers reported that the benefits of the screening programme included improved patient outcomes and increased awareness and knowledge of diabetic retinopathy. Barriers related to staffing issues and limited referral pathways. Image grading was performed by a variety of primary healthcare workers, with one responder indicating the utilisation of a diabetic retinopathy reading service. Of the people with fundus photos graded by the reading service, $26.2 \%$ were reported to have diabetes. Overall, $12.3 \%$ of eyes were diagnosed with diabetic retinopathy. Photo quality was rated as excellent in $46.2 \%$ of photos. Referral to an optometrist for diabetic retinopathy was recommended in $4.1 \%$ of cases, and to an ophthalmologist in $6.9 \%$ of cases.

Conclusions This nationwide diabetic retinopathy screening programme was perceived to increase access to diabetic retinopathy screening in regional, rural and remote areas of Australia. The telereading service has diagnosed diabetic retinopathy and other ocular pathologies in images it has received. Key barriers, such as access to ophthalmologists and optometrists, must be overcome to improve visual outcomes.

\section{INTRODUCTION}

Diabetic retinopathy (DR) is a microvascular complication of diabetes and the leading
Strengths and limitations of this study

- This is the first study to evaluate the implementation of a nationwide diabetic retinopathy screening programme funded by the Australian Government.

- To ensure that survey responders had a degree of familiarity with the cameras, only primary healthcare workers who had completed a training course at least six months prior were invited to participate.

- By evaluating all referrals to the reading service, all people who have been reviewed by telereading service for diabetic retinopathy have been characterised.

- There was a low response rate from primary healthcare workers to the survey.

- This survey does not capture the perspectives of people who underwent diabetic retinopathy screening through this programme.

cause of preventable blindness in the working-age population worldwide. ${ }^{12}$ Screening programmes for DR can reduce the risk of blindness by an estimated $56 \% .^{3}$ Certified incidence rates of vision loss from diabetes have dropped below those of inherited disorders in England and Wales, and this may be attributed to the implementation of a nationwide screening programme and better glycaemic control. ${ }^{4}$ In England's national screening programme, two-field mydriatic digital retinal photography is offered to people with diabetes annually, with an uptake of $82.8 \% .^{5}$ There are also established referral pathways for referral to an ophthalmologist for treatment and for assessment in those with poor-quality images. In New Zealand, screening programmes operate to national guidelines, where two to four fields are photographed, and this has also been associated with a reduction in vision-threatening DR. ${ }^{6}$

In Australia, DR is responsible for $1.4 \%$ of vision loss overall in non-Indigenous 
Australians and 5.2\% in Indigenous Australian peoples. ${ }^{7}$ This is reflective of the prevalence of DR in non-Indigenous (28.5\%) and Indigenous Australian peoples (39.4\%) with diabetes. ${ }^{8}$ Among other reasons, non-adherence to the recommended frequency for diabetic eye examinations has been identified as a contributing factor for DR-related vision loss, with $22.5 \%$ of non-Indigenous Australians and $47.3 \%$ of Indigenous Australian peoples with diabetes not complying with proposed examination schedules. ${ }^{9}$

Individuals living in remote areas have been identified as being at greater risk of non-adherence, ${ }^{10}$ which is a result of inequitable access to healthcare. ${ }^{11}$ In Australia, there is a maldistribution of eye care providers with approximately 12 optometrists and one ophthalmologist per 100000 people in outer regional, remote and very remote areas combined, compared with major cities that have 242 optometrists and four ophthalmologists per $100000 .{ }^{12}$ Although general practitioners (GPs) are also maldistributed, they are relatively more numerous in rural and remote areas compared with optometrists and ophthalmologists, with approximately 96 GPs per 100000 people. ${ }^{12}$ Since GPs can be trained to detect DR from retinal photos, ${ }^{13}$ they are well placed to act as a first-line contact and offer regular DR screening programmes in rural and remote areas. In addition to this, nurses and community health workers can be trained in the operation of retinal cameras, ${ }^{14}$ and therefore, can provide support to GPs as part of a DR screening programme.

Prior to the introduction of a nationwide programme in Australia, screening for DR in rural and remote areas was made available through local retinal photography programmes $^{15}$ the Visiting Optometrists Scheme, ${ }^{16}$ Rural Health Outreach Fund ${ }^{17}$ and teleophthalmology and mobile ophthalmology. ${ }^{18} 19$ There are currently 198 Indigenous-specific primary healthcare (PHC) facilities in Australia delivering care to 483000 clients, $81 \%$ of whom are Indigenous Australian peoples. ${ }^{20}$ In 2016, the Fred Hollows Foundation was engaged by the Australian Government to conduct the National Eye Care Equipment Inventory, with the aim of identifying which PHC facilities required additional equipment and support. ${ }^{21}$ Subsequently, to improve access to eye healthcare and visual outcomes for people with diabetes, the Australian Government announced funding for a national screening programme in $2017 .^{22}$

The resultant national screening programme was the Provision of Eye Health and Equipment Training (PEHET) programme. As a part of this programme, a roll-out of non-mydriatic retinal cameras to 162 PHC facilities was conducted, especially those in regional, rural and remote areas, to enable screening for DR among Indigenous Australian peoples. ${ }^{23}$ Non-Indigenous Australians were not excluded from the DR screening programme as the provision of these cameras additionally aimed to support the uptake of two recently introduced Medicare Benefit Schedule (MBS) item numbers directed at the assessment of visual acuity (VA) and bilateral retinal photography with a non-mydriatic retinal camera in people of Aboriginal and Torres Strait Islander descent (Item 12325) and
non-Indigenous Australians (Item 12326). ${ }^{24}{ }^{25}$ The purpose of these MBS item numbers is to reimburse GPs for services rendered, as part of Australia's universal health insurance scheme, and is only paid if the patient screened does not have (1) an existing diagnosis of DR, (2) VA less than 6/12 in either eye and (3) a difference of more than two lines of vision between the two eyes at the time of presentation.

As a part of this roll-out, personnel at each PHC facility receiving a retinal camera were also provided the opportunity to enrol in one or two training courses. The first course, for PHC workers, provided online and face-toface retinal camera training as well as mentoring and upskilling. ${ }^{26}$ The second course, conducted by the Centre for Eye Health (CFEH; Sydney, Australia), offered online training, for GPs and affiliated health workers, to interpret retinal images, identify common diabetic and nondiabetic ocular conditions and poor quality photographs, and classify levels of DR present in images. ${ }^{27} \mathrm{~A}$ temporary, free, centralised, telereading service provided by CFEH, a referral-only eye clinic, commenced in April 2019 as part of the PEHET programme to assist with interpretation and management decisions. Images are not sent automatically. Images requiring a second opinion are sent as needed to CFEH by the PHC facility.

This study investigated the implementation of the programme during its initial stages by identifying benefits and barriers of the PEHET programme as perceived by GPs and PHC workers. A secondary aim was to establish image interpretation pathways and the characteristics of people who had their retinal photos referred to CFEH for telereading.

\section{METHODS}

\section{Patient and public involvement}

The research question and outcome measures were driven by the need to evaluate the PEHET programme, which was the first nationwide screening programme for DR in Australia. Patients were not directly involved in the study and were not involved in the recruitment or conduct of this study. Results will be disseminated through the CFEH website and social media sites.

\section{Study design}

This study comprised two aspects: a survey (online supplemental material 1) to assess the perception and workflow of GPs and PHC workers at PHC facilities that received retinal cameras, and a review of remotely graded retinal photos to characterise target populations captured by this scheme.

An online survey was chosen as the research tool to assess the perceptions of GPs and PHC workers as this would facilitate easy access to potential responders over a large geographical area and allow responders to choose a time at their own convenience to offer their opinions and minimise any loss in their clinical time. ${ }^{28}$ The survey was designed in a collaborative effort among optometrists, ophthalmologists, medical professionals and a nurse and 
was implemented by two medical students (MAK and IWJ) and one optometrist (VK), all with experience in rural healthcare. The design of the survey was initially guided by the construct of 'knowledge and beliefs about the intervention' from the Consolidated Framework for Implementation Research (CFIR). ${ }^{29}$ Questions initially targeted the value placed on the retinal cameras by GPs and PHC workers. However, to assess their understanding of the rationale for the programme, a larger scope of questions was adopted during the design phase. To increase content validity, the survey was refined and reviewed by an expert panel of one ophthalmologist (AA), two optometrists (PK and VK), one registered nurse (BZ) and a GP. The final survey comprised 14 open-response and 25 closed-response questions concerning the responder's workplace and occupation, camera usage and training, image assessment and the awareness of DR. The CFIR was not used in the analysis.

The survey was administered on SurveyMonkey (San Mateo, California, USA) from 28 March 2019 to 29 November 2019. An invite to the survey was emailed by CFEH to GPs and PHC workers that had completed the second training course, with follow-up email and telephone contact. No other identifiable data was accessed for contact purposes. Each invitee could only respond to an email invitation once and IP addresses recorded by SurveyMonkey were used to ascertain unique responses. Surveys were otherwise completed anonymously. The target sample size encompassed 30 responders, ${ }^{30}$ comprised from a convenience sampling of GPs and PHC workers who had completed the second training course. To ensure that the cameras had been installed and used for a reasonable amount of time, only those who had completed the course within the preceding sixmonths were eligible for the study. Sampling did not take the number of facilities into account and no limits were placed on the number of staff able to respond per facility. Subsequently, no responses were excluded on this basis, since it could not be assumed that responders from the same facility shared the same experience with the programme.

In order to obtain information on the population initially benefiting from the implemented screening process, referral forms attached to all retinal photos transmitted to CFEH for photo grading were reviewed. The form, initially completed by the referring PHC facility, contained patient demographics, clinical history, and measured VA. After grading, this was retransmitted from CFEH to the referring facility, with a current diagnosis and other incidental non-DR findings noted, and feedback on the quality of the photos taken. Data were collected as a retrospective review of forms received by CFEH between the 2 April 2019 and 20th December 2019. The following deidentified data were extracted if reported: age, ethnicity, duration of diabetes (derived from year of diagnosis), glycated haemoglobin $\left(\mathrm{HbA}_{1 \mathrm{c}}\right)$, diabetes type, 2016 Remoteness Areas (derived from clinic location), ${ }^{31} \mathrm{VA}$, image quality, diagnosis, and management. Image quality, as determined by CFEH's ability to visualise the retinal microvasculature, was classified as they appeared in the form: excellent, adequate or poor. Diagnosis was classified as they appeared in the form: no DR, mild non-proliferative DR (NPDR), moderate NPDR, severe NPDR, PDR, high risk PDR, with diabetic macular oedema and other incidental findings.

\section{Qualitative content analysis}

Open survey responses were assessed using qualitative content analysis using a manifest approach. ${ }^{32}$ A coding list was inductively generated through consensus by researchers MAK, IWJ and VK. The data were coded and subsequently categorised by the same researchers. The analysis was performed using NVivo (V.12.6, QSR International, Melbourne, Australia). Data saturation was assessed during the coding process. Peer debriefing was performed by an external peer who was not involved in the research. To assess inter-rater reliability, Fleiss' kappa was calculated using SPSS (V.25, IBM). Descriptive statistics was used to assess the percentage of responses to open response questions and word count of the responses.

\section{Statistical analysis}

Reported postcodes of employment from survey responders were used to determine distinct PHC facilities. In postcodes with multiple PHC facilities, it was assumed that this corresponded with only one PHC facility. Descriptive statistics were used on quantitative data from the survey and all data derived from referral forms. Normality was assessed with the Shapiro-Wilk test. Wilcoxon signedrank test with Pratt's Method determined statistical significance for reported proportions of people screened prior and after camera installation and reported VA between right and left eyes. Marginal homogeneity test was used to compare the diagnoses and image quality of the right and left eyes. These analyses were performed with Excel (V.2005, Microsoft, Redmond, USA) and SPSS. P values less than 0.05 were considered significant.

\section{Researchers' characteristics and reflexivity}

The research team was composed of an ophthalmologist (AA), two optometrists (PK and VK), a registered nurse (BZ) and two medical students (MAK and IWJ), all with experience in rural healthcare and interests in diabetes care. Surveys were completed anonymously to ensure responders could be open with their experience. Responders were also only aware of the existence of two researchers (BZ and VK) from the participant consent form and email invite, respectively. A manifest approach to analysis was taken to reduce the effect of bias from the researchers' personal beliefs.

\section{RESULTS}

\section{Survey}

During the period that the study was conducted, 110 PHC workers completed the second training course 6 months prior. Of those contacted, 27 (25\%) completed the survey. Automatic email replies, indicating that the contacted worker was no longer employed at the practice, were 
Table 1 Demographics of survey responders

Survey responders, $\mathrm{n}(\%)$

\begin{tabular}{ll}
\hline Occupation & \\
$\begin{array}{l}\text { Aboriginal and Torres Strait } \\
\text { Islander Health Practitioner }\end{array}$ & $3(11)$ \\
General practitioner & $17(63)$ \\
Nurse & $7(26)$ \\
\hline Remoteness of practice location \\
Major city & $4(15)$ \\
Inner regional & $9(33)$ \\
Outer regional & $5(19)$ \\
Remote & $2(7)$ \\
Very remote & $7(26)$ \\
\hline
\end{tabular}

received for 13 (12\%) workers. No response was received from $69(63 \%)$ workers. All responders had completed the second training course for at least 6 months prior. The demographics of survey responders are listed in table 1. Most responders were GPs $(17,63 \%)$, and worked outside major cities $(23,85 \%)$. Postcode data indicated that the 27 survey responders represented 22 healthcare facilities. There were four sets of matching postcodes, with three duplicates and one triplicate. The triplicate postcode, 0872, may have corresponded to one to three PHC facilities, but for this study it was assumed that all responses were from the same PHC facility. Responders reported that $30 \%$ (IQR 31\%) of their patients were being screened for DR prior to the cameras being installed, rising to $65 \%$ (IQR 47\%, p<0.02) after installation. Healthcare workers from different disciplines were reported to be responsible for image grading (table 2), with 17 (63\%) responders indicating that there was more than one type of grader for their respective PHC facility.

\section{PHC workers' and GPs' experiences of the screening programme}

The kappa value for inter-rater reliability for coding was 0.94. During the coding process, $18(69 \%)$ codes were identified within the first ten responders, $8(31 \%)$ were identified within the next 10 responders and no further

Table 2 Reported health disciplines of image graders at 19 primary healthcare facilities

\begin{tabular}{|c|c|}
\hline Image grader & Survey responders, n (\%) \\
\hline $\begin{array}{l}\text { Aboriginal and Torres Strait } \\
\text { Islander Health Practitioner }\end{array}$ & $5(19)$ \\
\hline \multicolumn{2}{|c|}{$\begin{array}{l}\text { Central Diabetic Retinopathy } 1 \text { (4) } \\
\text { Reading Centre }\end{array}$} \\
\hline General practitioner & $14(52)$ \\
\hline Ophthalmologist & $6(22)$ \\
\hline Optometrist & $12(44)$ \\
\hline Nurse & $5(19)$ \\
\hline
\end{tabular}

codes were identified in the last seven responders. There was an overall response rate of $80.4 \% \pm 8.0 \%$ (range: $70.4 \%-100 \%)$ to the open response questions. The average word count for each response was $7.8 \pm 7.9$ words (range: $1-77$ words).

Eighteen $(66 \%)$ responders indicated positive benefits to the programme. The benefits of the screening programme as reported by PHC workers and GPs were classified into two categories. The first category pertained to perceived improved outcomes. Eleven $(41 \%)$ responders reported that the installation of retinal cameras had increased the screening and detection of DR in their patients, especially those who had not had an eye exam previously.

We have been able to screen people who have not previously been screened or who have had long lapses in screening. - GP 2, Very Remote

[There is] potential for early screening and detection for patients who fail to attend for their annual eye checks. - Practice nurse 1, Major City

Six $(22 \%)$ responders attributed some of this increase to opportunistic screening being delivered on-site and in a culturally appropriate manner.

Point of contact testing, [we are] not sending them away, we are doing it on the spot, and get[ting] them graded. - Practice nurse 5, Inner Regional

It was reported by five (19\%) responders that detecting DR through the programme had led to better outcomes for their patients. This included improved management within the scope of GPs, as well as identification of patients requiring further care.

Adjusting medications based on outcomes. - GP 11, Outer Regional

Improved diagnosis, referral and drop in HbA1c. GP 12, Very Remote

The result [is] that a number of people requiring urgent treatment have been identified. - GP 2, Very Remote

The second category was defined by perceived increased awareness and knowledge of DR. Six (22\%) responders perceived that the ability to show their patients their retinal photos enhanced communication, leading to people being better educated about their eyes and potentially more adherent to care.

I am able to show their photo and explain the image, normal or otherwise; increase their knowledge through education with the image; improves compliance; ensure timely eye review. - GP 17, Major City

Fantastic opportunity to show the effects of untreated diabetes and therefore aid compliance. - GP 12, Very Remote

Additionally, seven (26\%) responders found that camera rollout also benefited their own awareness and knowledge 
about DR. This was attributed to the training that was provided as a part of the rollout of the programme, which was well received by $17(63 \%)$ responders. The upskilling of staff led to increased confidence in discussing DR with their patients

I am more aware of eye health and assessment of it. Practice nurse 4, Outer Regional

Improved knowledge and skills in retinal image review. - GP 17, Major City

Although responders generally reported that the camera roll-out was beneficial, $17(63 \%)$ voiced barriers about the programme. The first category related to perceived issues with staff and staffing. Staff turnover was recognised by six (22\%) responders as a barrier to the programme's success.

Problem with training of nurses due to high staff turnover - GP 13, Very Remote

I am resigning soon and no-one else will take over - Aboriginal and Torres Strait Islander Health Practitioner (ATSIHP) 3, Very Remote

This incidentally was reinforced by the automatic email replies received during the study. Staff turnover resulted in a loss of time spent in training staff. It was suggested that training should be prioritised to staff who would be at the practice for the longer term or extended to more staff members.

[Training] should be offered to all those who show a strong interest in it. Firstly, to permanently based staff... and the locum comes second. - ATSIHP 2, Very Remote

Needs further education and promotion within the entire organisation so staff are aware that this is a service provided. - Practice nurse 1, Major City

More staff trained and actully completeing [sic] the screening not just one. - ATSIHP 3, Very Remote

Ten $(37 \%)$ responders indicated that they were not confident in their newly acquired skills and training and felt that they required supplementary and ongoing training. This was despite $74 \%$ (20) and 59\% (16) of responses indicating that on-site and online training, respectively, were at least at an adequate level. Furthermore, this was despite the support services that were available as part of the programme, where $33 \%$ (9) of responders reported receiving follow-up training and support.

I don't feel confident to assess images after one online course. - GP 13, Very Remote

More face to face training to develop the confidence of the workers. - Practice nurse 4, Outer Regional

Retinal photography was reported to be timeconsuming process by eight $(30 \%)$ responders to the open response questions. This was reinforced by the $56 \%$
(15) of responders who rated that the process was at time consuming in the closed response questions.

The systems of taking images, uploading the images to the electronic records, sending the images for reporting, ensuring the reports are read timely and acted upon appropriately is an inefficient process and [sic] at present. - GP 1, Very Remote

Time consuming, particularly the steps after the photo is taken. - ATSIHP 2, Very Remote

A lengthy procedure can discourage the use of the retinal camera. Ten $(37 \%)$ responders also described concerns over underutilisation stemming from fears that were not enough patients to screen in order to embed the recently acquired skills.

[I] wonder if they have numbers to be fluent with it. Many times, she [has] tried but forgets how to remain fluent. - GP 9, Remote

Low numbers so difficult to build up skills. - GP 15, Inner Regional

If the camera is underused, trained staff are unable to reinforce their skills with practice. Without practice, there is no opportunity for trained staff to become more familiar and time efficient with the retinal camera.

A common proposal to solve all these issues related to staff, as reported by ten responders, was to employ a dedicated staff member to take retinal photos.

Need to employ someone to take the images. - GP 10, Outer Regional

As long as we can have an eye nurse dedicated to it. GP 2, Very Remote

The second category related to the perceived absence of onward referral pathways. Optometrists were one of the preferred referral pathways for 59\% (16) of responders and ophthalmologists for $52 \%$ (14). Despite the utility of the programme and the use of retinal photography in detecting DR, seven $(26 \%)$ responders voiced problems related to access to further eye care.

But STILL not being able to get them to see the appropriate specialists. - GP 1, Very Remote

Unless there is a pathway... then loop isn't complete.

- GP 10, Outer Regional

It was revealed by these responders that it was difficult for people with newly detected referrable DR to receive timely care, due to the infrequent visits from eye care practitioners.

It is very difficult to get them to see the ophthalmologist within a month. - GP 1, Very Remote

Not many pathways given I am remote-ophthal [mologist] coming in 6 months. - GP 10, Outer Regional

Although eye care pathways are outside of the scope of the screening programme, ultimately, to improve 
Table 3 Reported clinical information and demographics of individuals referred to the Centre for Eye Health

\begin{tabular}{ll}
\hline Clinical information & \\
\hline Median age, years (SD) & $50.9(18.4)$ \\
Not reported, $\mathrm{n}(\%)$ & $20(13.8)$ \\
Ethnicity, n (\%) & \\
$\quad$ Non-Indigenous Australian & $53(36.6)$ \\
Indigenous Australian peoples & $92(63.4)$ \\
Median Duration of Diabetes, year (IQR) & $4(9)$ \\
Not reported, n (\%) & $126(86.9)$ \\
Type of diabetes, $\mathrm{n}(\%)$ & \\
Type 1 & $3(2.1)$ \\
Type 2 & $28(19.3)$ \\
Not reported & $114(78.6)$ \\
Median HbA & \\
Not reported, $\mathrm{n}(\%)$ & $64.1(25.8)$ \\
Median VA, logMAR (IQR) & $126(86.9)$ \\
Not reported, n (\%) & $0.12(0.23)$ \\
\hline
\end{tabular}

$\mathrm{HbA}_{1 \mathrm{c}}$, glycated haemoglobin; VA, visual acuity.

outcomes for all people with diabetes, the incompleteness of eye care pathways needs to be addressed.

\section{Target patient population}

CFEH received referral forms for 145 patients from 19 PHC facilities during the review period. The demographics of these patients are listed in table 3. Overall, only $38(26.2 \%)$ referral forms included medical information relevant to diabetes. Nonetheless, the CFEH telereading service graded most of the referred photos (267 photos, 92.1\%) for the presence of DR. There were no statistically significant differences between diagnoses $(p=0.45$; table 4$)$, image quality $(p=0.49)$ or median VA,

\begin{tabular}{ll}
\hline $\begin{array}{l}\text { Table } 4 \\
\text { Health }\end{array}$ & Diagnoses of 290 eyes graded by Centre for Eye \\
\hline Diagnosis & Eyes, $\mathbf{n}(\%)$ \\
\hline $\begin{array}{l}\text { DR Grading } \\
\text { No DR }\end{array}$ & $234(80.7)$ \\
\hline Mild NPDR & $4(1.4)$ \\
\hline Moderate NPDR & $23(7.9)$ \\
\hline Severe NPDR & $4(1.4)$ \\
\hline PDR & $1(0.3)$ \\
\hline High-risk PDR & $1(0.3)$ \\
\hline No grading recorded & $23(7.9)$ \\
\hline DMO & $4(1.4)$ \\
\hline Other incidental findings & $158(54.5)$ \\
\hline
\end{tabular}

DMO, diabetic macular oedema; DR, diabetic retinopathy; NPDR, non-proliferative diabetic retinopathy; PDR, proliferative diabetic retinopathy. where provided, between the right and left eyes, and thus, both eyes were analysed together in relevant subsequent analyses.

Of the 19 PHC facilities that referred images to $\mathrm{CFEH}$, three $(15.8 \%)$ were located in very remote, three $(15.8 \%)$ in remote, eight $(42.1 \%)$ in outer regional, four $(21.1 \%)$ in inner regional and one $(5.3 \%)$ in major city areas. Of the eyes graded for DR (267 eyes) by CFEH, 12.3\% (33) of eyes were diagnosed with DR (table 4). The CFEH telereading service rated $46.2 \% \quad(\mathrm{n}=134)$ of photos as excellent, $36.6 \%$ (106) as adequate, $15.5 \%$ (45) as poor and $1.7 \%$ (5) had not been rated. Referral to an optometrist was recommended in $54.5 \%$ (79) of cases, with 6 $(4.1 \%)$ of these cases for DR, $63(43.4 \%)$ for incidental findings unrelated to DR and $10(6.9 \%)$ for routine optometric care. Referral to an ophthalmologist was recommended in $17.9 \%(\mathrm{n}=26)$ cases, with $10(6.9 \%)$ of these cases for DR, and $16(11.0 \%)$ for other incidental findings.

\section{DISCUSSION}

In this study, we have shown that the perceived benefits of the introduction of on-site retinal photography revolved around improved outcomes, and increased awareness and knowledge of DR. There was a reported increase in the quantity of people being screened for DR through this programme, and which was reinforced from the CFEH telereading service's findings where DR was being detected. Hence, this programme has provided access to DR screening to its target population. However, there were concerns raised by GPs and PHC workers which related to staffing shortages and turnover, time constraints, embedment of skills and training, and absence of onward referral pathways.

This study has identified staff-related issues as a barrier to the programme. In particular, issues with a lack in diagnostic confidence or time constraints are similar to those previously highlighted by Australian GPs and American primary care providers. ${ }^{33}{ }^{34}$ In combination with the absence of onward referral pathways, it evident that workforce maldistribution and stability affects the entire patient care pathway - at the imaging of people, diagnosis of images and patient management. The geographical maldistribution of medical and allied health professionals is a consistent concern in rural and remote regions not only in Australia, ${ }^{35-38}$ but also in both developing and developed nations. ${ }^{39} 40$ This is especially pertinent to Indigenous Australian peoples who have faced historical and contemporary systemic discrimination and marginalisation. Workforce turnover rates of medical and allied health workers in remote areas are very high, especially in communities of Indigenous Australian peoples. ${ }^{41-43}$ Consequently, workforce turnover results in a loss of investment and time in training and upskilling healthcare workers to use retinal cameras and/or interpret retinal photos. The costs of replacing healthcare workers are high, ${ }^{43}$ and additional costs and time would be required 
to train and upskill replacement staff. Staff turnover was reinforced by the response rate to the survey, where one in nine trained healthcare workers contacted for the survey had already departed the PHC facility. Expanding the GP-specific MBS item numbers to reimburse PHC workers could provide a financial incentive to retain trained staff and potentially allow for a dedicated staff member for retinal imaging. Staffing shortages, which result from staff turnover, can contribute to the stated lack of time in incorporating retinal photography into the patient care pathway. This can then lead to further reduced time efficiency since the training and skills developed do not become embedded, which leads onto a cycle of inability to incorporate retinal photography.

Survey responders indicated that retinal images were assessed by collaborating optometrists and ophthalmologists, in addition to trained GPs, and generally not by a telereading service. This is corroborated by the relatively small number of PHC facilities that referred images to be graded by CFEH. As of December 2019, 132 sites had been trained in the use of retinal cameras, ${ }^{44}$ whereas CFEH received retinal photos from $19(14.3 \%)$ sites during April 2019 to December 2019. This may be indicative of variable access to locally well-developed patient referral and management pathways, but could also be amplified by issues with digital literacy. ${ }^{45} \mathrm{~A}$ review of graded retinal photos confirmed that DR was being detected through the screening, although at rates lower than expected. ${ }^{8}$ This may be attributed to the strict criteria for the MBS item numbers 12325 and $12326,{ }^{24}{ }^{25}$ which limits its usage to GPs only and to individuals not previously diagnosed with DR. Publicly available data indicate that the nationwide uptake of DR screening covered by these MBS item numbers has been slow (figure 1) ${ }^{46}$ Consequently, healthcare workers, especially non-GPs, may screen people outside the scope of the item numbers, including people with a VA less than $6 / 12$ or without diabetes, consistent with the potential integration of the programme resources with existing local patient management pathways. Additionally, the diabetic status in the majority of people referred to the telereading service was unknown. Consequently, if a high number of people without diabetes were actually screened, this would contribute to

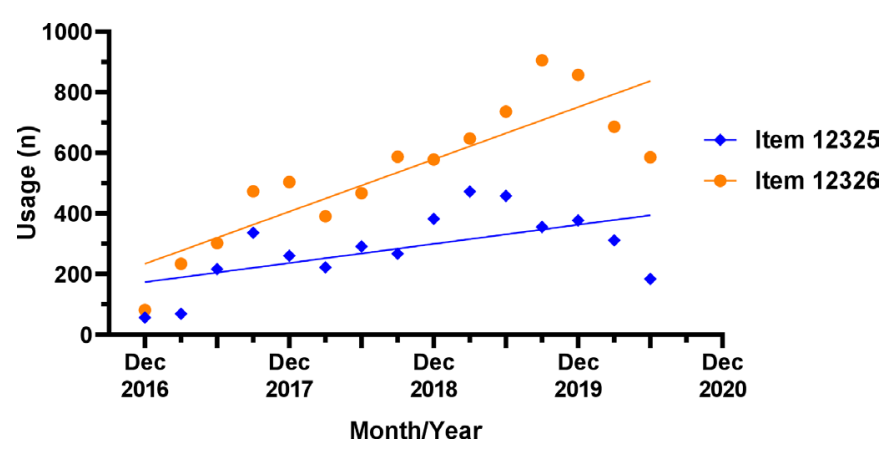

Figure 1 Publicly available data indicate that diabetic retinopathy screenings covered by the Medicare Benefits Scheme has been slowly increasing. a lower rate of DR detection. To address this, referrals should contain adequate clinical history including information identifying a diagnosis for diabetes and will ensure that appropriate individuals are being screened through the programme. The number of retinal photos that were of gradable quality were similar or higher than in other studies with photography-based screening models, ${ }^{47-50}$ indicative of the quality of the training, ease of camera use or the perseverance of the trained PHC workers to capture gradable photos. In contrast to DR, unrelated incidental findings were noted in more than half of the eyes, highlighting the utility of the programme and the centralised telereading service in diagnosing a range of ocular pathologies, and reinforcing the lack of eye care services in these areas.

Although the screening programme potentially provides opportunities to image people with diabetes and detect DR, and data suggest that these may be well integrated in locally well-developed patient management pathways, the reported lack of onward referral pathways may prevent people from accessing timely secondary care where such networks are not easily accessible. The importance of complete patient care pathways is reinforced by the review of graded retinal photos, where $72.4 \%$ of people required further eye care with an optometrist or ophthalmologist for DR, reduced VA and/or other ocular conditions. The continued and increased utilisation of teleophthalmology consultations in rural and remote areas of Australia could ameliorate this, ${ }^{51}$ with MBS item numbers available for optometrist-facilitated teleophthalmology consultations, although with strict criteria in scope ${ }^{18}$ Moreover, the Australian Government has existing programmes to tackle workforce maldistribution by providing targeted financial incentives to attract and retain medical practitioners, and allied health professionals to rural and remote areas. ${ }^{16} 1752$

This study invited all GPs and PHC workers who had participated in training for retinal image interpretation for at least 6 months prior, and therefore, were likely to have had a reasonable amount of time to familiarise themselves with the programme and offer individual standpoints on the implementation of the programme. However, we did not inquire as to whether the survey responders were permanent or locum staff. Moreover, we did not survey other healthcare workers who were potentially involved with screening but had not completed the second training course. Hence our sample does not represent this group of workers. Despite this, the scope of this study was limited to image interpretation training and retinal photography, and this would explain the high proportion of responders that identified as GPs, reflecting the target clinical population of the training. Although this study did not meet the target sample size, data saturation was reached after 20 participants as no further codes could be identified with additional data. The coding process was also highly concordant among the three coders. The survey component of this study is also limited by a low response rate, it accentuated the commonly 
acknowledged problem with high staff turnover, ${ }^{41-43}$ which was associated with a barrier identified in this study. Additionally, response rates of healthcare professionals in rural settings to surveys are known to be typically lower. ${ }^{53}$ Non-response and sampling bias analyses could not be conducted as we did not have the characteristics of the non-responders, nor the characteristics of the GPs and PHC workers who had completed the second training course. Within this context, it must be acknowledged that responses to the survey may have been biased in favour of the programme. Surveys from different responders from the same PHC facility were not excluded from the analyses. Despite this, it is also advantageous as different perspectives were captured from responders who may have different experiences with the programme. Also, this research does not report on the perspectives of people who underwent DR screening through this programme. This study did not review photos that were not referred to the telereading service, therefore the photos reviewed did not represent the entire population screened under the programme, but nonetheless still revealed a low uptake of the telereading service. Finally, this study was conducted while the programme was ongoing to assist in guiding potential improvements to the programme. As a result, not all PHC facilities had received cameras at the time the study was conducted, overall reducing the number of eligible GPs and PHC workers. Furthermore, adjustments to provide additional support to participating sites have been implemented with later stages of the programme and are likely to improve outcomes evaluated at the completion of the programme.

The nationwide roll-out of retinal camera infrastructure and training through the PEHET programme to facilitate DR screening has improved access for people with diabetes especially those residing in regional, rural and remote areas of Australia. However, its success may remain ephemeral unless the barriers identified in this study, particularly healthcare worker turnover and secured healthcare continuum, are addressed. Adjustments to address such issues are currently ongoing. A study conducted after the conclusion of the PEHET programme could determine the impact of these changes in comparison to presented results and further guide successful implementation of such a programme.

Acknowledgements The authors would like to acknowledge Sean Sivieng for work pertaining to data acquisition, and to the consortium responsible for the Provision of Eye Health and Equipment Training programme for verifying information pertaining to the programme.

Contributors VK was involved in drafting of the manuscript, and conception, acquisition, analysis and interpretation of the work. MAK was involved in critical review of the manuscript, and acquisition, analysis and interpretation of the work. IWJ was involved in critical review of the manuscript, and acquisition, analysis and interpretation of the work. PK was involved in critical review of the manuscript, and conception and interpretation of the work. AA was involved in critical review of the manuscript, and conception, and interpretation of the work. BZ was involved in critical review of the manuscript, and conception and interpretation of the work.

Funding VK is supported by the Australian Government through the Research Training Program (RSAP1000). Guide Dogs NSW/ACT provides support for the
Centre for Eye Health, and salary support for authors PK and BZ, and a top-up scholarship for VK (RSRT6016).

Competing interests VK and PK hold appointments at Centre for Eye Health. Centre for Eye Health is a member of the consortium delivering the Provision of Eye Health and Equipment Training programme. VK does not have any direct or indirect involvement with the project.

Patient consent for publication Not required.

Ethics approval This study adhered to the Declaration of Helsinki and ethics approval was provided by the University of New South Wales (UNSW) Human Research Ethics Committee (reference HC190087), and by the UNSW Human Research Advisory Panel (reference HC190078).

Provenance and peer review Not commissioned; externally peer reviewed.

Data availability statement Data are available on reasonable request. Summary data sets presented in the publication can be accessed on request. Individual data cannot be shared as per patient confidentiality agreements.

Supplemental material This content has been supplied by the author(s). It has not been vetted by BMJ Publishing Group Limited (BMJ) and may not have been peer-reviewed. Any opinions or recommendations discussed are solely those of the author(s) and are not endorsed by BMJ. BMJ disclaims all liability and responsibility arising from any reliance placed on the content. Where the content includes any translated material, BMJ does not warrant the accuracy and reliability of the translations (including but not limited to local regulations, clinical guidelines, terminology, drug names and drug dosages), and is not responsible for any error and/or omissions arising from translation and adaptation or otherwise.

Open access This is an open access article distributed in accordance with the Creative Commons Attribution Non Commercial (CC BY-NC 4.0) license, which permits others to distribute, remix, adapt, build upon this work non-commercially, and license their derivative works on different terms, provided the original work is properly cited, appropriate credit is given, any changes made indicated, and the use is non-commercial. See: http://creativecommons.org/licenses/by-nc/4.0/.

ORCID iD

Vincent Khou http://orcid.org/0000-0002-4696-9226

\section{REFERENCES}

1 Bourne RRA, Stevens GA, White RA, et al. Causes of vision loss worldwide, 1990-2010: a systematic analysis. Lancet Glob Health 2013;1:e339-49.

2 Twigg SM, Wong J. The imperative to prevent diabetes complications: a broadening spectrum and an increasing burden despite improved outcomes. Med J Aust 2015;202:300-4.

3 Rohan TE, Frost CD, Wald NJ. Prevention of blindness by screening for diabetic retinopathy: a quantitative assessment. BMJ 1989;299:1198-201.

4 Liew G, Michaelides M, Bunce C. A comparison of the causes of blindness certifications in England and Wales in working age adults (16-64 years), 1999-2000 with 2009-2010. BMJ Open 2014;4:e004015.

5 Scanlon PH. The English national screening programme for diabetic retinopathy 2003-2016. Acta Diabetol 2017;54:515-25.

6 Reda E, Dunn P, Straker C, et al. Screening for diabetic retinopathy using the mobile retinal camera: the Waikato experience. $N Z$ Med J 2003;116:U562.

7 Foreman J, Xie J, Keel S, et al. The prevalence and causes of vision loss in Indigenous and non-Indigenous Australians: the National eye health survey. Ophthalmology 2017;124:1743-52.

8 Keel S, Xie J, Foreman J, et al. The prevalence of diabetic retinopathy in Australian adults with self-reported diabetes: the National eye health survey. Ophthalmology 2017;124:977-84.

9 Foreman J, Keel S, Xie J, et al. Adherence to diabetic eye examination guidelines in Australia: the National eye health survey. Med J Aust 2017;206:402-6.

10 Gibson AA, Humphries J, Gillies M, et al. Adherence to eye examination guidelines among individuals with diabetes: an analysis of linked health data. Clin Exp Ophthalmol 2020;48:1229-38.

11 Australian Institute of Health and Welfare. Rural \& remote health. Canberra, Australia: Australian Institute of Health and Welfare, 2020. https://www.aihw.gov.au/reports/rural-health/rural-remote-health/ contents/rural-health

12 [dataset] Department of Health. Data from: health workforce data, 2021. Available: https://hwd.health.gov.au/ 
13 Andonegui J, Zurutuza A, de Arcelus MP, et al. Diabetic retinopathy screening with non-mydriatic retinography by general practitioners: 2-year results. Prim Care Diabetes 2012;6:201-5.

14 Murray RB, Metcalf SM, Lewis PM, et al. Sustaining remote-area programs: retinal camera use by Aboriginal health workers and nurses in a Kimberley partnership. Med J Aust 2005;182:520-3.

15 Tapp RJ, Svoboda J, Fredericks B, et al. Retinal photography screening programs to prevent vision loss from diabetic retinopathy in rural and urban Australia: a review. Ophthalmic Epidemiol 2015;22:52-9.

16 Department of Health. Visiting optometrists scheme grant programme guidelines. Canberra, Australia: Australian Government, 2015. https://www1.health.gov.au/internet/main/publishing.nsf/ Content/FDF591BFF47D044BCA257E0B0006334C/\$File/vos_ guidelines.pdf

17 Department of Health. Rural health outreach fund. Canberra, Australia: Australian Government, 2020. https://www1.health.gov. au/internet/main/publishing.nsf/Content/651B62BEE7DE74CFCA25 7BF0001C95A3/\$File/RHOF-Service-Delivery-Standards-From-1July-2020.pdf

18 Bartnik SE, Copeland SP, Aicken AJ, et al. Optometry-facilitated teleophthalmology: an audit of the first year in Western Australia. Clin Exp Optom 2018;101:700-3.

19 Fu S, Jeyaraj J, Turner AW. Evaluating the impact of the lions outback vision mobile ophthalmology service. Clin Exp Ophthalmol 2019:47:956-7.

20 Australian Institute of Health and Welfare. Indigenous Australians' use of health services. Canberra, Australia: Australian Institute of Health and Welfare, 2020. https://www.aihw.gov.au/reports/australiashealth/indigenous-australians-use-of-health-services

21 Fred Hollows Foundation. 2016 annual report. Sydney, Australia: Fred Hollows Foundation, 2017. https://www.hollows.org/Upload/ FHFV3/Media/au/pdf/Other\%20file\%20downloads/2016-AnnualReport.pdf

22 Vision 2020 Australia. Vision 2020 Australia welcomes funding for Indigenous eye health. Melbourne, Australia: Vision 2020 Australia, 2017. https://www.vision2020australia.org.au/media/2017-04-27/ vision-2020-australia-welcomes-funding-for-indigenous-eye-health/

23 Brien Holden Vision Institute. The provision of eye health equipment and training (PEHET) program. Sydney, Australia: Brien Holden Vision Institute, 2020. https://bhvi.org/brien-holden-foundation/where-wework/australia/pehet/

24 Department of Health. Medicare benefits schedule - item 12325. Canberra, Australia: Australian Government, 2020. http://www9. health.gov.au/mbs/fullDisplay.cfm?type=item\&qt=ItemID\&q= 123252020

25 Department of Health. Medicare benefits schedule - item 12326. Canberra, Australia: Australian Government, 2020. http://www9. health.gov.au/mbs/fullDisplay.cfm?type=item\&qt=ItemID\&q= 123252020

26 Brien Holden Vision Institute. Provision of eye health equipment and training project outline. Sydney, Australia: Brien Holden Vision Institute, 2020. https://bhvi.org/download/4087/

27 Centre for Eye Health Education. Diabetic retinopathy: a training course 2020. Sydney, Australia: Centre for Eye Health, 2020. https:// www.centreforeyehealth.com.au/learning-portal/

28 Jones TL, Baxter MAJ, Khanduja V. A quick guide to survey research Ann R Coll Surg Engl 2013;95:5-7.

29 Damschroder LJ, Aron DC, Keith RE, et al. Fostering implementation of health services research findings into practice: a consolidated framework for advancing implementation science. Implement Sci 2009;4:50.

30 Bengtsson $M$. How to plan and perform a qualitative study using content analysis. NursingPlus Open 2016;2:8-14.

31 Australian Bureau of Statistics. The Australian statistical geography standards (ASGS) remoteness structure. Canberra, Australia: Australian Bureau of Statistics, 2020. https://www.abs.gov.au/ websitedbs/D3310114.nsf/home/remoteness+structure

32 Kleinheksel AJ, Rockich-Winston N, Tawfik H, et al. Demystifying content analysis. Am J Pharm Educ 2020;84:7113.
33 Ting D, Ng J, Morlet $\mathrm{N}$, et al. Diabetic retinopathy--screening and management by Australian GPs. Aust Fam Physician 2011;40:233-8.

34 Liu Y, Zupan NJ, Swearingen R, et al. Identification of barriers, facilitators and system-based implementation strategies to increase teleophthalmology use for diabetic eye screening in a rural US primary care clinic: a qualitative study. BMJ Open 2019;9:e022594.

35 Tennant M, Kruger E, Shiyha J. Dentist-to-population and practiceto-population ratios: in a shortage environment with gross maldistribution what should rural and remote communities focus their attention on? Rural Remote Health 2013;13:2518.

36 Smith JD, White C, Roufeil L, et al. A national study into the rural and remote pharmacist workforce. Rural Remote Health 2013;13:2214.

37 Kiely PM, Chakman J. Optometric practice in Australian Standard Geographical Classification--Remoteness Areas in Australia, 2010. Clin Exp Optom 2011:94:468-77.

38 Madden AC, Simmons D, McCarty CA, et al. Eye health in rural Australia. Clin Exp Ophthalmol 2002;30:316-21.

39 Naylor KB, Tootoo J, Yakusheva O. Geographic variation in spatial accessibility of U. S. healthcare providers. PLoS One 2019;14:e0215016.

40 Lehmann U, Dieleman M, Martineau T. Staffing remote rural areas in middle- and low-income countries: a literature review of attraction and retention. BMC Health Serv Res 2008;8:19.

41 Russell DJ, Zhao Y, Guthridge S, et al. Patterns of resident health workforce turnover and retention in remote communities of the Northern Territory of Australia, 2013-2015. Hum Resour Health 2017;15:52

42 Wakerman J, Humphreys J, Russell D, et al. Remote health workforce turnover and retention: what are the policy and practice priorities? Hum Resour Health 2019;17:99.

43 Chisholm M, Russell D, Humphreys J. Measuring rural allied health workforce turnover and retention: what are the patterns, determinants and costs? Aust J Rural Health 2011;19:81-8.

44 Brien Holden Vision Institute. Provision of eye health and equipment training project update. Sydney, Australia: Brien Holden Vision Institute, 2019.

45 Cheng C, Beauchamp A, Elsworth GR, et al. Applying the electronic health literacy lens: systematic review of electronic health interventions targeted at socially disadvantaged groups. J Med Internet Res 2020;22:e18476.

46 Department of Human Services. Medicare item reports. Canberra, Australia: Australian Government, 2020. http://medicarestatistics. humanservices.gov.au/statistics/do.jsp?_PROGRAM=\% 2Fstatistics\%2Fmbs_item_standard_report\&DRILL=ag\&group= $12325 \% 2 \mathrm{C} 12326 \& \mathrm{VAR}=$ services $\&$ STAT $=$ count \&RPT $F M T=b y+$ state $\&$ PTYPE=month\&START_DT $=201904 \& E N D \_D T=201912$

47 Brazionis L, Jenkins A, Keech A, et al. Diabetic retinopathy in a remote Indigenous primary healthcare population: a central Australian diabetic retinopathy screening study in the telehealth eye and associated medical services network project. Diabet Med 2018;35:630-9.

48 Mak DB, Plant AJ, McAllister I. Screening for diabetic retinopathy in remote Australia: a program description and evaluation of a devolved model. Aust J Rural Health 2003;11:224-30.

49 Glasson NM, Crossland LJ, Larkins SL. An innovative Australian outreach model of diabetic retinopathy screening in remote communities. J Diabetes Res 2016;2016:1-10.

50 Larizza MF, Hodgson LA, Fenwick EK, et al. Feasibility of screening for diabetic retinopathy at an Australian pathology collection service: a pilot study. Med J Aust 2013;198:97-9.

51 O'Day R, Smith C, Muir J, et al. Optometric use of a teleophthalmology service in rural Western Australia: comparison of two prospective audits. Clin Exp Optom 2016;99:163-7.

52 Department of Health. Workforce incentive program guidelines. Canberra, Australia: Australian Government, 2020. https://www. health.gov.au/sites/default/files/documents/2021/01/workforceincentive-program-guidelines.pdf

53 Brtnikova M, Crane LA, Allison MA, et al. A method for achieving high response rates in national surveys of U.S. primary care physicians. PLoS One 2018;13:e0202755. 